\title{
Oviposition, flight and walking capacity at low temperatures of four aphid parasitoid species (Hymenoptera: Aphidiinae)
}

\author{
AlAin LANGER ${ }^{1,2}$, Guy BOIVIN ${ }^{3}$ and ThIERRy HANCE ${ }^{1}$ \\ ${ }^{1}$ Université catholique de Louvain, Centre de recherche sur la biodiversité, Unité d'écologie et de biogéographie, \\ Place Croix du Sud 4-5, 1348 Louvain-la-Neuve, Belgium; e-mail: hance@ecol.ucl.ac.be \\ ${ }^{2}$ Centre Nature de Botrange, Haute-Fagnes-Eifel Nature Park, B-4950, Robertville, Belgium; e-mail: hautesfagneseifel@skynet.be \\ ${ }^{3}$ Centre de Recherche et de Développement en Horticulture, Agriculture et Agroalimentaire Canada, 430, boul. Gouin, \\ Saint-Jean-sur-Richelieu, Québec, Canada J3B 3E6; e-mail: boiving@agr.gc.ca
}

Keywords. Flight activity, walking activity, temperature threshold, oviposition, Aphidius sp., cereal aphid, spring activity

\begin{abstract}
Precocious activity of parasitoids is a key factor for cereal aphid control. We investigated the oviposition, flight and walking capacities at low temperature of four aphid parasitoids (Aphidius rhopalosiphi, A. ervi, Praon volucre, P. gallicum) on one of their aphid hosts (Sitobion avenae). Oviposition behaviour was tested at 2, 4, 6, 8, 10, 15 and $20^{\circ} \mathrm{C}$, under a photoperiod of $12 \mathrm{~h}$ light. Some females of $A$. rhopalosiphi oviposited at $6^{\circ} \mathrm{C}$ while the percentage of parasitization below $10^{\circ} \mathrm{C}$ remained low for the other species. The proportion of males decreased with temperature for A. ervi, P. volucre and P. gallicum but not for A. rhopalosiphi. For all species, flight and walking activities increased with temperature, Aphidius species being active at lower temperature than Praon species. Field captures showed that the activity threshold for $A$. rhopalosiphi is $12^{\circ} \mathrm{C}, 15^{\circ} \mathrm{C}$ for $A$. ervi and $P$. volucre, and $19.5^{\circ} \mathrm{C}$ for $P$. gallicum. These results are discussed regarding the potential of these four species for aphid control.
\end{abstract}

\section{INTRODUCTION}

In temperate climates, low temperature plays a key role in the regulation of population growth, especially when the cold period covers not only the winter season, but also part of autumn and spring. Cold affects population dynamics of insects mainly by influencing development time (Campbell et al., 1974; Ankersmit, 1983), longevity (Starý, 1970), mortality (Sømme, 1982; Leather et al., 1993) and reproduction (Carrière \& Boivin, 2001). Indeed, we expect that individuals that remain active instead of undergoing diapause during cold periods, should increase their fitness, providing they are able to reproduce even at low temperatures. The southern corn rootworm, Diabrotica undecimpunctata howardi (Barber) (Coleoptera: Chrysomelidae), has developed a particular feature allowing it to reproduce even during the winter. D. undecimpunctata howardi mates at the beginning of winter and both males and females raise their body temperature above ambient temperature by basking in direct sunlight (Meinke \& Gould, 1987).

Furthermore, temperature may also affect population dynamics by influencing synchronization between parasitoids and hosts, either by preventing parasitoid activity during a critical period, or by acting on the development time of either host or parasitoid. The latter has been demonstrated for the braconid Apanteles bignellii (Marshall) and its host, the butterfly Euphydryas aurinia (Rottemburg) (Porter, 1983). This parasitoid only attacks the larval stage of its host, which is present in April and May. The fourth, fifth and sixth larval instars of E. aurinia are dark colored and develop rapidly under clear skies because they increase their body temperature due to solar radiation. A. bignellii overwinters as larvae and adults emerge in spring; the larval development depends on ambient temperature. Under cool but sunny spring conditions the parasitoids develop slowly, while E. aurinia caterpillars progress rapidly. Adult parasitoids then emerge when the majority of E. aurinia had pupated and hence are no more suitable hosts. In such case, temperature causes a loss of synchronization between the parasitoid and host.

In this study, we investigated the reproduction capacities at low temperatures of four aphid parasitoid species: Aphidius rhopalosiphi (DeStefani-Peres), A. ervi (Haliday), Praon gallicum (Starý) and P. volucre (Haliday) (Hymenoptera: Braconidae: Aphidiinae). All four species are solitary koinobiont endoparasitoids of the grain aphid Sitobion avenae (Fabricius). For this aphid species, holocyclic, but also anholocyclic overwintering is common in western Europe (Blackman \& Eastop, 1984), and consequently $S$. avenae remains a potential host for parasitoids during winter owing to its anholocyclic populations. There is sufficient evidence to show that at least part of wheat aphid parasitoid populations are active throughout the cold period (Dedryver \& Gellé, 1982; Vorley, 1986; Langer et al., 1997). To increase their fitness, individuals must have a low temperature threshold for activity: they must be able to fly and forage for anholocyclic aphids, which are at low densities between autumn and spring, and to oviposit in these hosts. The lower the temperature thresholds are, the greater the fitness gain could be.

\section{MATERIAL AND METHODS}

Laboratory cultures of aphids ( $S$. avenae) and parasitoids were established from individuals collected in winter wheat 
fields during summer 1996 at Louvain-la-Neuve, Belgium $\left(50.3^{\circ} \mathrm{N}\right.$ latitude). Aphids were reared on winter wheat seedlings, Triticum aestivum (L.) (c.v. Torfrida), at $20^{\circ} \mathrm{C}$ under a photoperiodic regime of $16 \mathrm{~L}: 8 \mathrm{D}$. Parasitoids were reared under the same conditions.

\section{Oviposition capacities}

Oviposition behaviour was tested at $2,4,6,8,10,15$ and $20^{\circ} \mathrm{C}$, under a photoperiod of $12 \mathrm{~h}$ light. The short photoperiod characteristic of the cold period in Belgium was chosen. During $24 \mathrm{~h}$, approximately 70 second and third instars of $S$. avenae were provided to one pair (male + female) of each parasitoid species under different temperature conditions. Parasitoids were $24 \mathrm{~h}$ old, and females were naive and mated. Each treatment was repeated 8 times. After $24 \mathrm{~h}$, the parasitoids were removed and aphids were reared at $20^{\circ} \mathrm{C}$ under $16 \mathrm{~L}: 8 \mathrm{D}$ regime until mummies were formed. At emergence, the adults were sexed. For each repetition, percentage of parasitism (number of mummies / total number of aphids) was calculated, and following $\arcsin \sqrt{ }$ transformation, was analyzed by a three-way ANOVA. The effects tested were the species, the temperature and the date of the replicates (all replicates were not done the same day). Pairwise comparisons were performed by a SNK-test (with critical $p=0.05)$ (Proc GLM, SAS Institute Inc., 1989). Within each parasitoid species, sex-ratios (male proportion) obtained at different temperatures were compared by $\mathrm{Chi}^{2}$-tests (critical $\mathrm{p}=$ 0.05). Within each temperature, sex-ratios were compared between species by paired $\mathrm{Chi}^{2}$-tests (critical $\mathrm{p}=0.05$ ); sexratios of the temperatures 2 to $10^{\circ} \mathrm{C}$ were pooled together due to the low level of parasitism.

\section{Flight capacities}

The flight capacity of the four parasitoid species was tested at $10,12,14$ and $16^{\circ} \mathrm{C}$. Five males and five females, one-day old, were placed in a $3 \mathrm{~cm}$ wide Petri dish at the bottom of an upright, opaque cylinder of $9 \mathrm{~cm}$ width and $20 \mathrm{~cm}$ height. A transparent sticky lid was placed at the top of the cylinder. Insects were attracted to the top by the light of a small neon tube. To prevent parasitoids walking off, the Petri dish was surrounded by water. The number of parasitoids glued on the lid (meaning that they had flown) was recorded after four hours. After square root transformation, the numbers of parasitoids glued were compared by a three-way ANOVA, testing the "parasitoid species" effect, the "temperature" effect and the "date of repetition" effect. Pairwise comparisons were performed by SNK-tests (critical $\mathrm{p}=0.05$ ). The temperatures with 0 and $50 \%$ flight activity $\left(\mathrm{FT}_{0}\right.$ and $\mathrm{FT}_{50}$ respectively) were determined for each species using a PROBIT test (Proc PROBIT, SAS Institute Inc., 1989).

\section{Walking capacities}

The walking capacity of the four parasitoid species was tested at 8,16 and $22^{\circ} \mathrm{C}$. Isolated females were placed in the center of a glass Petri dish in a constant temperature chamber and filmed during the experiment. The camera was coupled to a computer and the walking velocity (walking distance/time) was calculated using Observer software (Noldus technology). Periods of rest were not taken into account. Twelve females were tested per parasitoid species. Velocities were compared using an ANOVA with species and temperature as factors and a SNK test was then applied to data obtained at different temperatures and species.

\section{Field activity}

This experiment was conducted from the first week of January 1997 to the end of April 1997 in two experimental wheat fields at Louvain-la-Neuve and Lauzelle, in the Belgian sand-loamy region of Brabant. The fields were $\pm 60 \mathrm{~m}$ long and $\pm 40 \mathrm{~m}$ wide. Ten pots each containing ten wheat plants infested with 80 second and third instars of $S$. avenae were exposed in the field in order to obtain estimates of parasitoid activity. In each field, the pots were placed in basins containing soap-suds to prevent field contamination with aphids. Aphid escape was not possible as they returned to laboratory before they reached the winged adult stage. A $0.4 \times 0.6 \mathrm{~m}$ transparent roof of $0.6 \mathrm{~m}$ height protected the trap plants and aphids against rain and snow during winter. From $1^{\text {st }}$ April, a net protected the potted aphids against Syrphidae and Coccinellidae, while parasitoids were small enough to pass through the meshes $(0.5 \times 0.5 \mathrm{~cm})$. After one week of exposure, the pots were removed and transported back to the laboratory. The remaining aphids were reared at $20^{\circ} \mathrm{C}$ until the development of mummies. The percentage parasitism (number of mummies/total aphids) per pot was then calculated, and parasitoid sexes were determined after adults had hatched. Pots with fewer than 10 aphids were excluded from the analysis. Meteorological data was obtained from a station of the Institut d'astronomie et de géophysique Georges Lemaître from the Université catholique de Louvain situated $1 \mathrm{~km}$ from the experiemental field.

\section{RESULTS \\ Oviposition capacities}

A. rhopalosiphi parasitized $2.4 \%$ of the aphids presented at $4{ }^{\circ} \mathrm{C}$ due to two females having parasitized 1 and 7 aphids respectively. Percentage parasitization of $A$. rhopalosiphi increased gradually with $5.0 \pm 2.2 \%$ and $7.0 \pm$ $2.7 \%$ of the aphids at $6^{\circ} \mathrm{C}$ and $8^{\circ} \mathrm{C}$ respectively, while the percentage parasitization of the other species remained below $4 \%$ until $10^{\circ} \mathrm{C}$ (Fig. 1). At $10^{\circ} \mathrm{C}$, the percentage of parasitization of $A$. rhopalosiphi and $A$. ervi was $19.0 \pm$ $4.9 \%$ and $16.6 \pm 6.1 \%$ respectively, while $P$. volucre and P. gallicum reached only $8.4 \pm 3.4 \%$ and $7.1 \pm 1.8 \%$ respectively. A significant difference was found between species $[\mathrm{F}(3,33)=3.78 ; \mathrm{p}=0.0194]$, and more precisely between $A$. rhopalosiphi and the other species
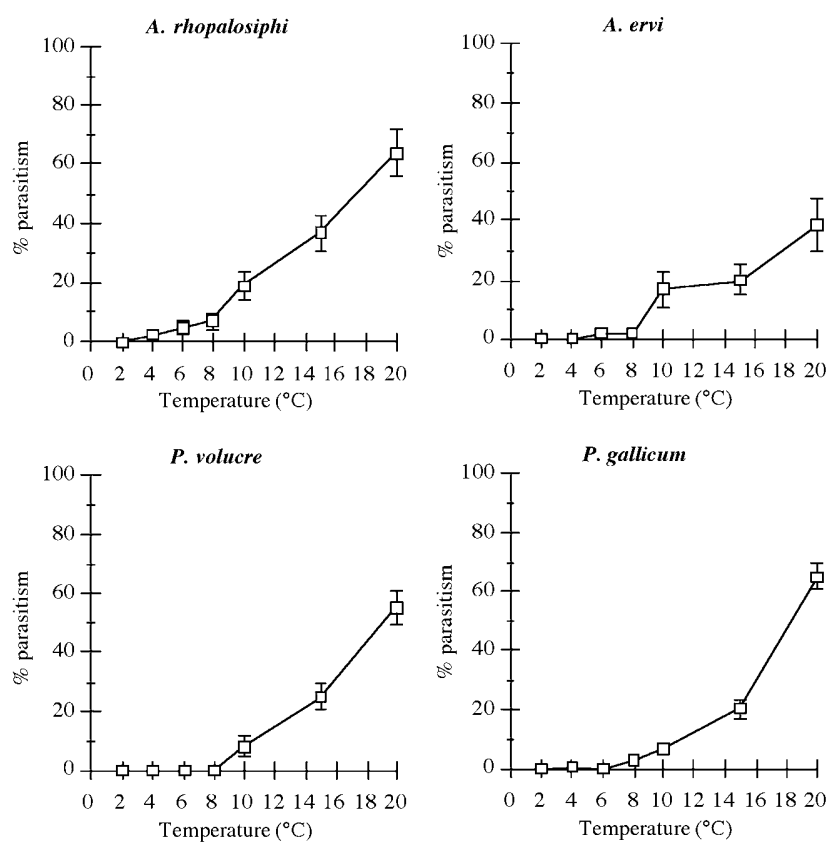

Fig. 1. Effect of temperature $\left({ }^{\circ} \mathrm{C}\right)$ on the mean percentage parasitization $( \pm \mathrm{SE})$ of $S$. avenae by four aphid parasitoid species. A. rhopalosiphi differs signicantly from the other species. 


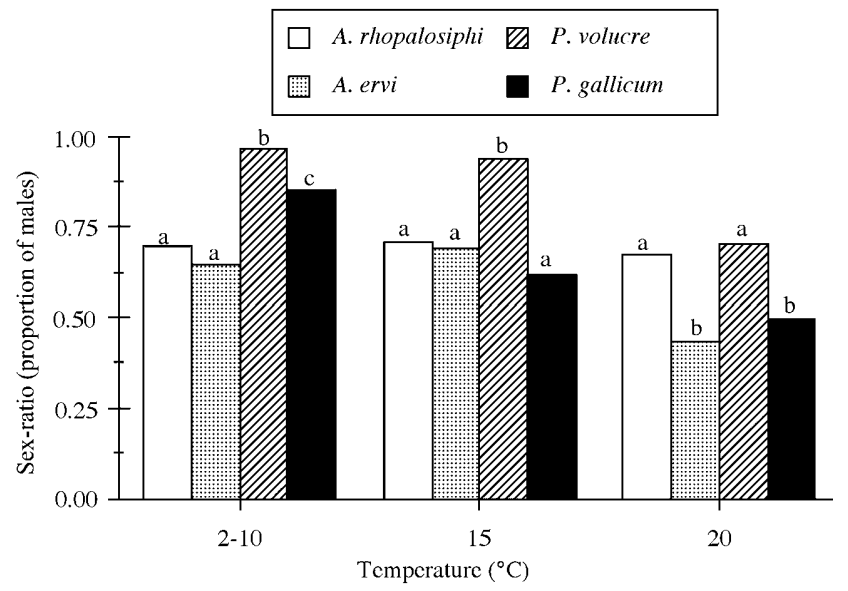

Fig. 2. Effect of temperature during oviposition on the offspring sex-ratio. Within each temperature, species with the same letter are not significantly different $(\mathrm{p}>0.05)$.

(SNK-test). For the four species, no parasitism was observed at $2^{\circ} \mathrm{C}$ indicating that the temperature threshold is near that value.

For all species, the percentage of parasitization differed significantly between temperatures $[\mathrm{F}(6,43)=102.37 ; \mathrm{p}$ $=0.0001]$. The interaction "temperature* species" was not significant $[\mathrm{F}(18,128)=1.31 ; \mathrm{p}=0.1924]$ indicating that significant differences between temperatures are valid for all species, and vice-versa. The SNK-test showed significant differences between $2,8,10,15$ and $20^{\circ} \mathrm{C}$.

Sex-ratio varied with temperature (Fig. 2). The proportion of females increased significantly with increasing temperature for $A$. ervi $\left(\mathrm{Chi}^{2}=21.39, \mathrm{df}=2, \mathrm{p}=0.001\right)$, $P$. volucre $\left(\mathrm{Chi}^{2}=40.49, \mathrm{df}=2, \mathrm{p}=0.001\right)$ and $P$. gallicum $\left(\mathrm{Chi}^{2}=22.61, \mathrm{df}=2, \mathrm{p}=0.001\right)$, but not for $A$. rhopalosiphi whose sex-ratio varied between 0.67 and 0.70 $\left(\mathrm{Chi}^{2}=0.82, \mathrm{df}=2, \mathrm{p}=0.662\right)$. Differences between species were brought out by pairwise $\mathrm{Chi}^{2}$-tests (Fig. 2). Between 2 to $15^{\circ} \mathrm{C}, P$. volucre showed a significantly higher sex-ratio than the three other species. At $20^{\circ} \mathrm{C}$, sex-ratios of $A$. ervi and $P$. gallicum were significantly lower than those of $A$. rhopalosiphi and $P$. volucre.

\section{Flight capacities}

For all parasitoid species, flight activity increased significantly with temperature $[\mathrm{F}(3,18)=314.17 ; \mathrm{p}=$

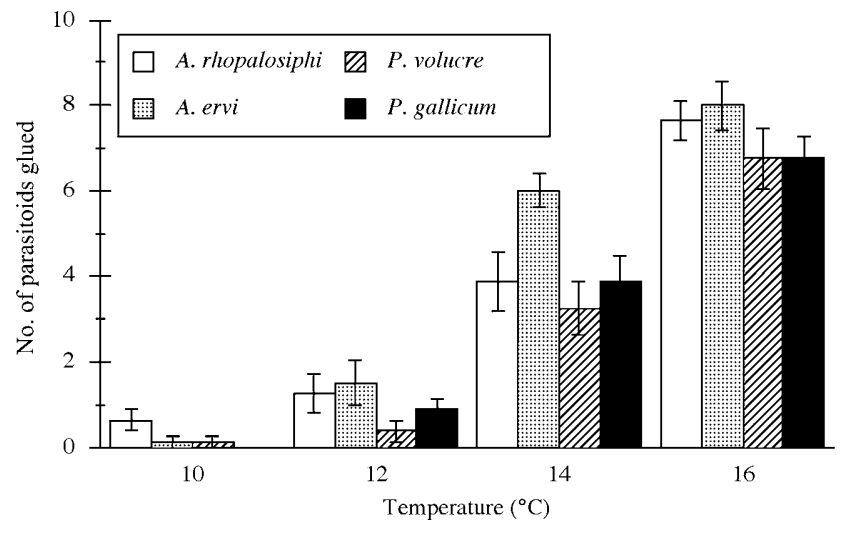

Fig. 3. Effect of temperature on the flight activity (mean \pm $\mathrm{SE}$ ) of four aphid parasitoid species.

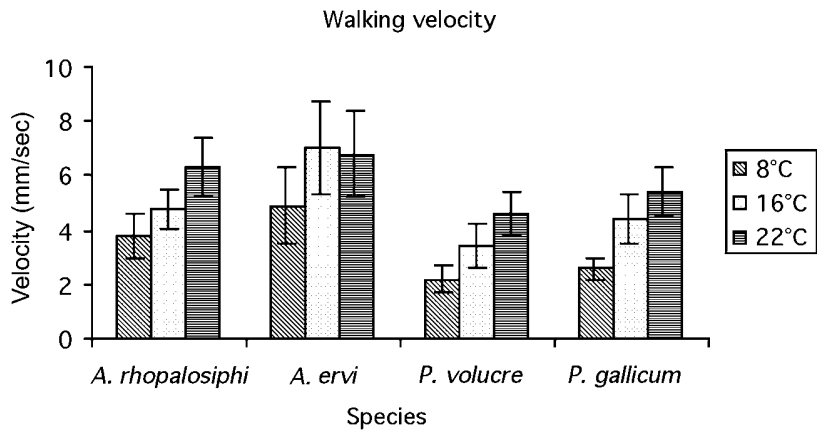

Fig. 4. Effect of temperature on the walking velocity (mean \pm SE) of four aphid parasitoid species.

0.0001] (Fig. 3). Significant differences were found between all temperatures tested (SNK-test). The interaction "temperature*species" in the ANOVA test was not significant $[\mathrm{F}(9,54)=1.37 ; \mathrm{p}=0.227]$.

Significant differences were also found between species $[\mathrm{F}(3,18)=4.72 ; \mathrm{p}=0.0134]$. Both species of the genus Aphidius exhibited significantly greater flight capacities than the two species of the genus Praon, excepted in the case of $A$. rhopalosiphi in comparison with $P$. gallicum (SNK-test).

The PROBIT analysis showed that for all parasitoid species tested, the lower flight temperature threshold $\left(\mathrm{FT}_{0}\right)$ was near $10^{\circ} \mathrm{C}$ (Table 1). No significant difference appeared between species, because fiducial limits overlaped. The temperature allowing 50\% flight activity $\left(\mathrm{FT}_{50}\right)$ was the lowest for $A$. ervi, and it differed significantly from the $\mathrm{FT}_{50}$ of $P$. volucre and $P$. gallicum.

\section{Walking capacities}

Walking velocities decreased significantly $(\mathrm{p}<0.001)$ with decreasing temperature except for $A$. ervi at $16^{\circ} \mathrm{C}$ and $22^{\circ} \mathrm{C}$ (Fig. 4), but no interaction "temperature*species" was found $(\mathrm{p}=0.123)$. For all temperatures, the Aphidius species walked significantly more rapidly than Praon spp., with all species differing significantly (SNK test, $\mathrm{P}<0.05$ ). At $8^{\circ} \mathrm{C}, A$. ervi and $A$. rhopalosiphi were still moving at a velocity of $4.8 \pm 1.4$ and $3.7 \pm 0.8 \mathrm{~mm} / \mathrm{s}$, respectively, whereas $P$. volucre and $P$. gallicum reached only $2.1 \pm 0.5$ and $2.5 \pm 0.4 \mathrm{~mm} / \mathrm{s}$.

\section{Field activity}

Field results are shown in Fig. 5: the percentage of parasitism per pot of trap plants is represented as a function of the highest maximum temperature recorded during the corresponding week of capture. First temperatures of activity were influenced by the date of capture: the earlier

TABLE 1 . Temperatures enabling $0 \%$ and $50 \%$ flight activity $\left(\mathrm{FT}_{0}\right.$ and $\left.\mathrm{FT}_{50}\right)$ of four parasitoid species.

\begin{tabular}{lllll}
\hline Temperature $\left({ }^{\circ} \mathrm{C}\right)$ & A.rhopalosiphi & A. ervi & P. volucre & P. gallicum \\
\hline $\mathrm{FT}_{0}$ & 8.7 & 9.3 & 10.4 & 9.9 \\
lower/upper fl & $7.3 / 9.6$ & $8.2 / 10.0$ & $9.2 / 11.2$ & $8.7 / 10.8$ \\
$\mathrm{FT}_{50}$ & 14.4 & 13.9 & 15.0 & 14.8 \\
lower/upper fl & $14.0 / 14.9$ & $13.6 / 14.3$ & $14.7 / 15.4$ & $14.5 / 15.3$ \\
\hline
\end{tabular}

$\mathrm{fl}$ - fiducial limit 


\section{A. rhopalosiphi}

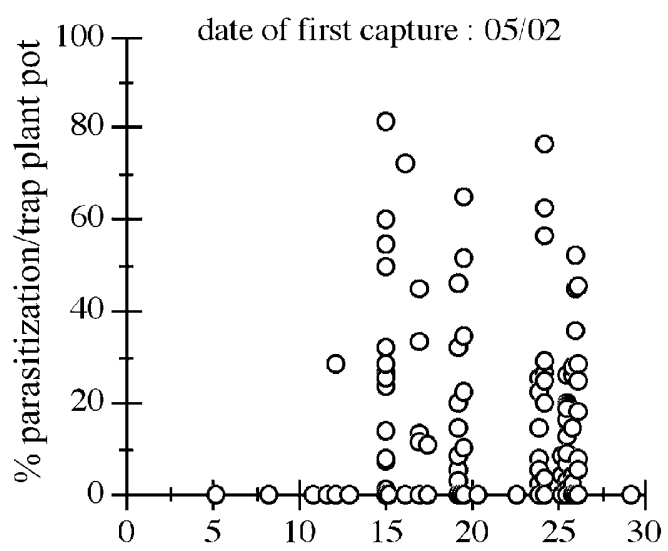

Maximum temperature during the week $\left({ }^{\circ} \mathrm{C}\right)$

\section{P. volucre}

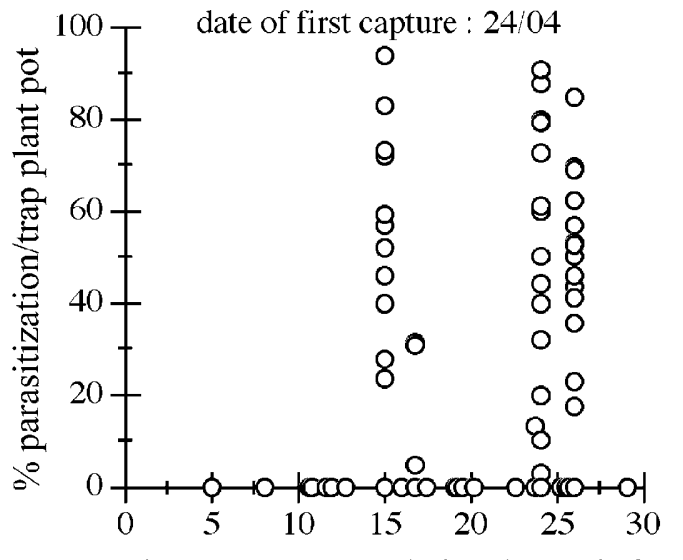

Maximum temperature during the week $\left({ }^{\circ} \mathrm{C}\right)$
A. ervi

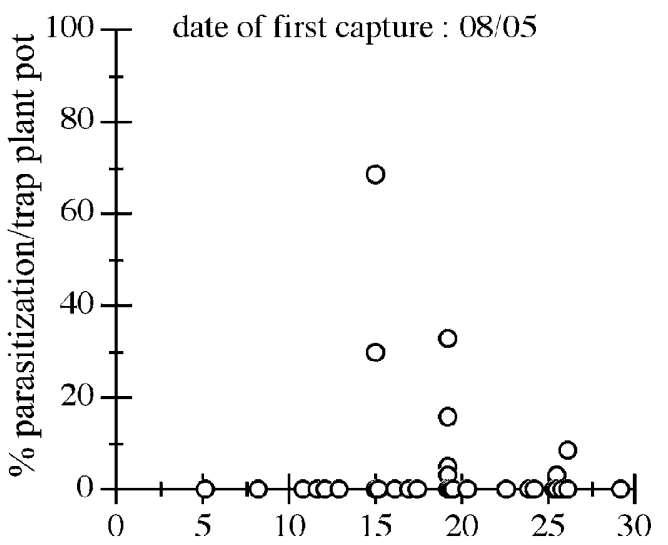

Maximum temperature during the week $\left({ }^{\circ} \mathrm{C}\right)$

P. gallicum

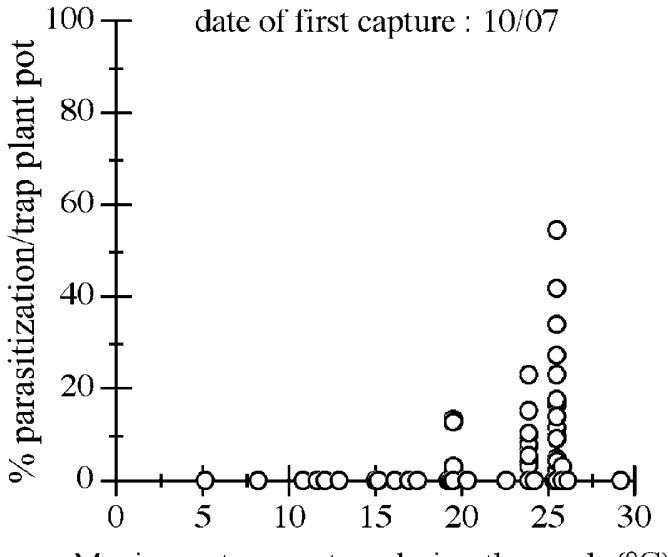

Maximum temperature during the week $\left({ }^{\circ} \mathrm{C}\right)$

Fig. 5 Percentage parasitization recorded in pots of trap plants in response to maximum temperature $\left({ }^{\circ} \mathrm{C}\right)$ recorded during the corresponding week of capture.

the first capture was, the lower the temperature. The first capture of $A$. rhopalosiphi occurred during the week of the 5 th February at $12^{\circ} \mathrm{C}$. Fig. 6 presents the number of days per month with a maximum temperature above 12 and $14^{\circ} \mathrm{C}$ in successive winters $1991-1992$ to $1996-1997$. $A$. ervi and $P$. volucre were captured for the first time during the week of the 24th April and the 8th May respectively; at a temperature of $15^{\circ} \mathrm{C}$ for both species. $P$. gallicum occurred only later in summer (10th July) when temperature reached $19.5^{\circ} \mathrm{C}$.

\section{DISCUSSION AND CONCLUSION}

Our results showed that temperatures above $10^{\circ} \mathrm{C}$ are needed to allow parasitoids to oviposit. Below this temperature few parasitized aphids were observed for $A$. rhopalosiphi, A. ervi and $P$. gallicum, and none for $P$. volucre. Prinsloo et al. (1993) studied the effect of temperature on the oviposition behaviour of Aphelinus asychis (Walker) (Hymenoptera: Aphelinidae) and Aphidius colemani (Viereck) (Aphidiinae). The relationship between oviposition and temperature was different for the two species: $A$. asychis showed a sigmoidal relationship, while oviposition of $A$. colemani increased with temperature in an exponential manner. For the former, they calculated a temperature threshold of $11.1^{\circ} \mathrm{C}$; the latter laid the first eggs at $5^{\circ} \mathrm{C}$, but a threshold could not be calculated because, as in our study, data were weakly correlated with temperature. Aphelinidae and Aphidiinae seem thus to have different oviposition patterns at low temperatures. Such differences could be due to differences in trade-offs between performance at a given temperature and resulting fitness gain at the larval or adult stage. When lines of Trichogramma pretiosum Riley were tested for their parasitization capacity at several temperatures, a change of performance at one temperature resulted in an opposite change at the distant temperature (Carrière \& Boivin 2001). Therefore, the performance of parasitoids at a given temperature not only results from the potential fitness gain at that temperature but also from potential fitness gains or losses at other temperatures.

Offspring sex-ratio increased with a decrease in temperature. This effect of low temperatures is well known 


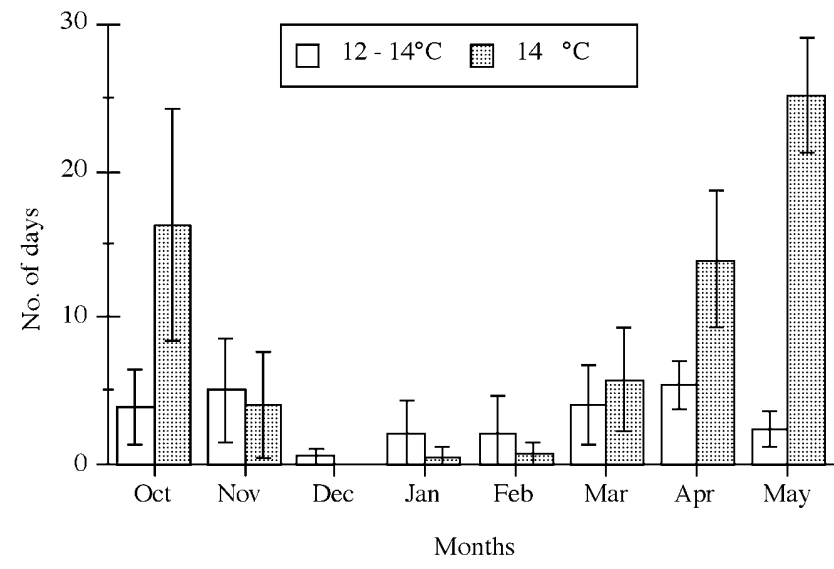

Fig. 6. Number of days (mean $\pm \mathrm{SD}$ ) with a maximum temperature above 12 and $14^{\circ} \mathrm{C}$ in successive winters $1991-92$ to 1996-97 in Belgium.

for parasitic wasps (King, 1987), and it can act in different ways: sterilizing males, decreasing the rate of movement to the point that mating is rare, incapacitating sperm (King, 1987) or the spermatheca, or influencing the female choice when ovipositing. In our experiments, females were mated and the high proportion of males must be due to one of the three latter hypotheses. The production of a male-biased sex ratio could be an advantage in terms of fitness. Indeed, King (1987) pointed out that if a long duration between emergence and mating indicates a shortage of males in the population, selection should favour females that increase the sex-ratio of their offspring as the duration of this period increases. During the cold period, the population of active parasitoids is rather low, and thus, the probability for a female to encounter a male is also low. So, if females increase the proportion of males in their offspring, the chance of mating will increase. It will be interesting to confirm this hypothesis at high temperature.

The temperature enabling flight activity in the laboratory was near $10^{\circ} \mathrm{C}$ for all species studied, allowing interpatch disperal. However, flight activity in the field was not recorded under $12^{\circ} \mathrm{C}$ for $A$. rhopalosiphi, $19^{\circ} \mathrm{C}$ for $P$. gallicum and $15^{\circ} \mathrm{C}$ for $A$. ervi and $P$. volucre. For the two latter species, the temperature threshold in the field was thus similar to the $\mathrm{FT}_{50}$ in laboratory (Table 1). Abraham (1975) also studied the effect of temperature on the flight activity of parasitic Hymenoptera in the field, and he observed a threshold temperature of $13^{\circ} \mathrm{C}$ for most Ichneumonoidea. This is similar to those obtained for $A$. rhopalosiphi, A. ervi and P. volucre in our field experiment. It seems clear that the temperature threshold in the field was influenced by the dates of capture. For instance, the first capture of $P$. gallicum was in mid-July and so its high temperature threshold derived from field results is probably not realistic. This species is more characteristic of the summer, although it can fly and oviposit at lower temperatures.

The four species showed some walking activity at $8^{\circ} \mathrm{C}$, below the threshold for flying. Walking is an important part of intra-patch searching behaviour and the fact that walking was observed at low temperature indicates that parasitism remains possible at this temperature if females are already in the vicinity of an aphid colony. In our case, all individuals moved with little difference in speed contrary to Suverkrop et al. (2001) who observed an important interindividual variability of walking activities of Trichogramma brassicae at $12^{\circ} \mathrm{C}$ probably linked to the fact that the activity threshold of this species is close to that temperature.

Levels of parasitism observed in the field are the result of flight, walking and oviposition activities. Furthermore, field observations showed relatively high variations for a given temperature. Two factors are probably responsible for this variation: first, each point represents the result of one trap plant pot, and each pot was not necessarily found by parasitoids, and secondly, other parameters influenced parasitoid activity in the field such as humidity, wind and precipitation (Vater, 1971). For example, Abraham (1975) tested the flight capacities of Braconidae under different levels of humidity but constant temperature, and he observed more flights at high humidity. Extremes of relative humidity, below 25 or above $90 \%$, cause drastic reductions in the activity of Ichneumonids and Braconids (Juillet, 1964). Furthermore, relative humidity is known to be strongly linked to temperature: low humidity and high temperatures are known to considerably affect life expectancy and reproductive success of small insects like parasitoids (Starý, 1970). Fournier \& Boivin (2000a) drawn the attention on the importance of solar radiation in parallel with temperature explaining the field activity of two species of Trichogrammatidae.

Weisser et al. (1997) as well as Fink \& Völkl (1995) showed that any kind of rain (drizzle, rain or showers) prevented not only the departure from a shoot, but also foraging activities of Aphidius rosae (Haliday) within the shoot. Juillet $(1960,1964)$ presented opposite observations: light intermittent rain tended to stimulate flight activity of parasitic Hymenoptera. Wind seems to prevent parasitoid dispersal but not oviposition (Vater, 1971; Fink \& Völkl, 1995; Weisser et al., 1997). Again, Juillet (1964) qualified this assertion, because he observed a reduction in flight only above a certain threshold $(0.76$ $\mathrm{m} / \mathrm{s}$ ). A. rhopalosiphi flies only when wind velocity does not exceed $3 \mathrm{~m} / \mathrm{s}$ (Vater, 1971). The effect of wind on dispersal was clearly demonstrated by Fournier \& Boivin (2000b) who showed that level of parasitization of Ephestia kuehniella Zeller eggs (Lepidoptera: Pyralidae) by Trichogramma evanescens Westwood was lower upwind (26\%) than downwind (67\%).

Aphid parasitoids are able to forage and oviposit from $10^{\circ} \mathrm{C}$ onwards. They seem thus to have the features enabling them to increase their fitness even during the cold period in Belgium. The mean number of days with the maximum temperature above 12 or $14^{\circ} \mathrm{C}$ between October and May is indicated in Fig. 6. It appears that, even in December, temperatures still allow the activity of the four species considered. Consequently, even during winter, quiescent individuals should gain fitness by remaining in an active stage, providing that hosts are 
available and that synchronization is guaranteed. These observations were confirmed by Legrand et al. (2004) who showed that $A$. rhopalosiphi may have a strong regulatory effect on $S$. avenae population growth in early spring.

Synchronization between wheat aphids and their parasitoids is influenced by temperature. First, parasitoid development is dependent on temperature. Consequently, the number of parasitoid generations that can be completed during winter or early spring is affected by temperature. This situation is complicated by cultural practices. Wheat fields are sown in autumn, and the sowing date affects the migration of aphids and parasitoids into wheat fields before winter and thus also the amount of development of parasitized aphids that can occur before and during winter (Vorley, 1986, Dewar \& Carter, 1984). Therefore, it may be useful to maintain alternative hosts on plants that stay in the vicinity of wheat fields throughout the year to decrease the dependance of parasitoid population on sowing dates.

Secondly, quiescent parasitoids that may emerge during winter may show lower winter mortality than their hosts (Langer \& Hance, 2000). So, even if temperatures allow parasitoid activity, fitness gain is not ensured if no suitable host is available.

Thirdly, parasitoid efficacy in the control of wheat aphid populations in summer depends on their ability to maintain their own populations on alternative hosts during the spring, especially in May (Langer \& Hance, 2004). If the summer conditions are such that they reduce parasitoid activity, parasitoid populations may decline considerably before the arrival of wheat aphids with a comparable reduction in aphid population control. However, our results indicate that this hypothesis is improbable, because most days in May temperatures reach above the activity threshold.

Walter \& Dixon (1984) studied the flight capacities of S. avenae at low temperatures and the $\mathrm{FT}_{50}$ they obtained was $19^{\circ} \mathrm{C}$ and thus higher than that of its parasitoids. This means that parasitoids are able to forage and to oviposit at temperatures that hinder aphids from dispersing. In the frame of biological control, this feature is of particular importance, because it allows the parasitoids to exert pressure on wheat aphids before their dispersion to other sites. It confirms that in the framework of biological control of wheat aphids, parasitoid activity is important even in seasons that allow only a lesser degree of activity.

Our results show that wheat aphid parasitoids have the possibility to increase their fitness if they remain active during winter. To complete our results, it would be interesting to study how much the fitness of parasitoids active during winter is influenced by adult longevity and by the number of parasitoid generations that hatch during winter Indeed, efficacy of parasitoids during the cold period should depend on the number of "good weather" days they encounter. On the other hand, larvae will not develop as long as the temperature is low, and hence, adults may only emerge during a "good weather" period.
ACKNOWLEDGEMENTS. This study was supported by the Service de la Recherche Agronomique, Ministère des Classes Moyennes et de l'Agriculture. We are greatfull to P. Dogot for his invaluable help during the experiments, and to C. Gérin, A. Levie and D. Stilmant for their constructive advices.

\section{REFERENCES}

Aвraham R. 1975: Über die Wirkung der Temperatur auf die Flugaktivität parasitischer Hymenopteren. Z. Angew. Entomol. 79: 113-123.

AnKersmit G.W. 1983: Aphidiids as parasites of the cereal aphids Sitobion avenae and Metopolophium dirhodum. In Cavalloro R. (ed.): Aphid Antagonists. Balkema, Rotterdam pp. 42-49.

Blackman R.L. \& Eastop V.F. 1984: Aphids on the World's Crops. An Identification Guide. John Wiley \& Sons, New York, 466 pp.

Campbell A., Frazer B.D., Bilbert N., Gutierrez A.P. \& MACKAUER M. 1974: Temperature requirements of some aphids and their parasites. J. Appl. Ecol. 11: 431-438.

CARriÈre Y. \& BoIvin G. 2001: Constraints on the evolution of thermal sensitivity of foraging in Trichogramma: Genetic trade-offs and plasticity in maternal selection. Am. Nat. 157: $570-581$.

Dedryver C.A. \& Gellé A. 1982: Biologie des pucerons des céréales dans l'ouest de la France. IV. Etude de l'hivernation de populations anholocycliques de Rhopalosiphum padi L., Metopolophium dirhodum Wlk. et Sitobion avenae F. sur repousses de céréales, dans trois stations de Bretagne et du Bassin parisien. Acta Oecol. (Oecol. Appl.) 3: 321-342.

Dewar A.M. \& CARTER N. 1984: Decision trees to assess the risk of cereal aphid outbreaks in summer in England. Bull. Entomol. Res. 74: 387-398.

FINK U. \& VÖLKL W. 1995: The effect of abiotic factors on foraging and oviposition success of the aphid parasitoid, Aphidius rosae. Oecologia 103: 371-378.

FourNier F. \& Borvin G. 2000a: Impact of meteorological conditions on spatial dispersion of Trichogramma evanescens and T. pretiosum (Hym.: Trichogrammatidae) in cabbage. Ann. Soc. Entomol. Fr. 35: 471-475.

Fournier F. \& BoIvin G. 2000b: Comparative dispersal of Trichogramma evanescens and Trichogramma pretiosum (Hymenoptera: Trichogrammatidae) in relation to environmental conditions. Envir. Entomol. 29: 55-63.

JuILLET J.A. 1960: Some factors influencing the flight activity of hymenopterous parasites. Can. J. Zool. 38: 1057-1061.

JUILLET J.A. 1964: Influence of weather on flight activity of parasitic Hymenoptera. Can. J. Zool. 42: 1133-1141.

KING B.H. 1987 : Offspring sex ratios in parasitic wasps. Quart. Rev. Biol. 62: 367-396.

Langer A., Stilmant D., Verbois D. \& Hance T. 1997: Seasonal activity and distribution of cereal aphid parasitoids in Belgium. Entomophaga 42: 185-191.

LANGer A. \& HanCE T. 2000: Overwintering strategies and cold hardiness of two aphid parasitoid species (Hymenoptera: Braconidae: Aphidiinae). J. Insect Physiol. 46: 671-676.

LANGER A. \& Hance T. 2004: Enhancing parasitism of wheat aphids through apparent competition: a tool for biological control. Agric. Ecosyst. Environ. 102: 205-212.

Leather S.R., Walters K.F.A., BALE J.S. 1993: The Ecology of Insect Overwintering. Cambridge University Press, Cambridge, $255 \mathrm{pp}$.

Legrand M.A., Colinet H., Vernon P. \& Hance T. 2004: Autumn, winter and spring dynamics of aphid-parasitoid interactions. Ann. Appl. Biol. (in press) 
MeinKe L.J. \& Gould F. 1987: Thermoregulation by Diabrotica undecimpunctata howardi and potential effects on overwintering biology. Entomol. Exp. Appl. 45: 115-122.

PorTer K. 1983: Multivoltinism in Apanteles bignellii and the influence of weather on synchronization with its host Euphydryas aurinia. Entomol. Exp. Appl. 34: 155-162.

Prinsloo G.J., Hewitt P.H. \& VAn der Westhuizen M.C. 1993: The effect of temperature on oviposition behaviour and success of two parasitoids of the Russian Wheat Aphid, Diuraphis noxia (Kurdjumov) (Hemiptera: Aphididae). Afr. Entomol. 1: 189-193.

SAS Institute Inc. 1989: SAS/STAT® User's Guide. Version 6. 4th ed. Vol. 2. Cary, NC: SAS Institute Inc.

Søмme L. 1982: Supercooling and winter survival in terrestrial arthropods. Comp. Biochem. Physiol. (A) 73: 519-543.

Starý P. 1970: Biology of Aphid Parasites. Series Entomologica. Vol. 6. Dr. Junk, The Hague, 643 pp.
Suverkrop B.P., Bigler F. \& Van Jenteren J.C. 2001: Temperature influences walking speed and walking activity of Trichogramma brassicae (Hym.: Trichogrammatidae). J. Appl. Entomol. 125: 303-307.

VATER G. 1971: Ausbreitung und Wanderverhalten parasitischer Hymenopteren. Biol. Rundsch. 9: 281-303.

VORLEY W.T. 1986: The activity of parasitoids (Hymenoptera: Braconidae) of cereal aphids (Hemiptera: Aphididae) in winter and spring in southern England. Bull. Entomol. Res. 76: 491-504.

Walters K.F.A. \& Dixon A.F.G. 1984: The effect of temperature and wind on the flight activity of cereal aphids. Ann. Appl. Biol. 104: 17-26.

Weisser W.W., Völkl W. \& Hassell M.P. 1997: The importance of adverse weather conditions for behaviour and population ecology of an aphid parasitoid. J. Anim. Ecol. 66: 386-400.

Received October 10, 2003; revised February 10, 2004; accepted March 19, 2004 